\title{
Os corpos no espaço: confrontação ao simulacro democrático e resistência à estetização da política
}

\section{Bodies in Space: Confrontacion Against Democratic Simulacrum and Resistance to "Aestheticization" of Politics}

\author{
Polyana Pereira Coelho \\ Universidade Federal de Minas Gerais, Belo Horizonte, Minas Gerais / Brasil \\ polyanapcoelho@gmail.com
}

Resumo: O ano de 2016 iniciou-se, no Brasil, num quadro de "instabilidade política", termo usado pela grande mídia para referir-se às disputas pelo poder político que vinham ocorrendo desde 2013, quando irromperam no cenário brasileiro manifestações populares de grandes proporções. Desde a chegada do século XXI, uma mudança no quadro da mobilização popular marcou o desenvolvimento da luta de classes mundial. Embora difusas e aparentemente desconectadas, as diversas mobilizações que ocorreram em diversos continentes, retomaram a centralidade do espaço urbano enquanto palco da práxis política. No Brasil, as discussões sobre o espaço urbano adquiriram relevância ao final da década de 1960, quando a urbanização ampliou-se exponencialmente. Desde então o espaço urbano está em crise: marcado pelos muros, pelos conflitos, pela violência e pela disputa espacial na qual a aliança entre classe dominante e o Estado tem vencido sempre. Contudo, novas experiências insurgentes têm demonstrado que é possível construir espaços de resistência frente ao avanço do capital. As ocupações escolares demonstram como o desgaste com as péssimas condições de vida nas cidades podem levar à efervescência da luta por direitos. Nesse sentido, buscou-se investigar as insurgências que se utilizam da desobediência civil e da ocupação do espaço como estratégia de luta contra os projetos de dominação da consciência e da colonização do saber. As mobilizações que ressurgiram no Brasil a partir de 2013 demonstraram que é possível reconfigurar a luta urbana e reativar a esfera de discussão dos movimentos sociais, da juventude e dos excluídos fortalecendo a construção de projetos contrahegemônicos.

Palavras-chave: Espaço urbano; insurgência; desobediência civil; ocupações escolares. 


\begin{abstract}
The year 2016 began in Brazil in a context of "political instability", a term used by the mainstream media to refer to the disputes over political power that has been taking place since 2013, when popular manifestations of large proportions erupted in the Brazilian scene. Since the turn of the 21st century, a shift in popular mobilization has marked the development of the world class struggle. Although diffuse and apparently disconnected, the various mobilizations that took place in several continents, have returned to the centrality of the urban space as a stage of political praxis. In Brazil, discussions about urban space became relevant at the end of the 1960s, when urbanization expanded exponentially. Since then the urban space is in crisis: marked by walls, conflicts, violence and the space dispute in which the alliance between the ruling class and the state has always won. However, new insurgent experiences have shown that it is possible to build spaces of resistance against the advance of capital. School occupations demonstrate how the wear and tear of poor living conditions in cities can lead to the effervescence of the struggle for rights. In this sense, we sought to investigate the insurgencies that use civil disobedience and the occupation of space as a strategy to fight against projects of domination of consciousness and colonization of knowledge. The mobilizations that have resurged in Brazil since 2013 have shown that it is possible to reconfigure the urban struggle and reactivate the sphere of discussion of social movements, youth and the excluded, strengthening the construction of counterhegemonic projects.
\end{abstract}

Keywords: Urban space; insurgency; civil disobedience; occupations.

Recebido em: 14 de junho de 2017.

Aprovado em: 22 de agosto de 2017.

\title{
1 Marcas modernas da estetização da política
}

A expressão "estetização da política" empregada por Walter Benjamin (1969) no texto "A obra de arte na era de sua reprodutibilidade técnica" pode ser trazida para os dias atuais quando da observação das relações cotidianas de produção e absorção de imagens, signos e significados. A expressão de Benjamin, utilizada para designar o processo de apropriação das tecnologias de reprodução cinematográfica pelo nazi-fascismo para fins de dominação ideológica, muito nos remete à forma pela qual, na atualidade, o "simulacro" democrático se ancora na circulação de imagens pela mídia convencional para a sua sobrevivência. 
Em suas observações sobre o crescimento da massa de proletários no século XX e sobre a relação do fascismo para com tais trabalhadores, Benjamim afirma que o fascismo "queria organizar as massas, sem mexer no regime de propriedade" (BENJAMIN, 1969, p. 33). Assim, pensava-se em "solucionar o problema, permitindo às massas, não certamente fazer valer seus direitos, mas exprimi-los. [...] O fascismo quer permitir-lhes que se exprimam, porém conservando o regime" (BENJAMIN, 1969, p. 33). Tratava-se, portanto, de uma participação falseada, que foi orientada pelo fascismo e subsidiada pela ampla divulgação de imagens coletivas de uma massa organizada em torno ao líder e ao seu projeto político. A propaganda e a utilização dessas imagens eram voltadas para o convencimento da classe trabalhadora como um todo da importância política do fascismo, de suas atividades e estratégias resultando no culto à guerra. A essa participação falseada podemos associar a expressão "estetização da política" de Benjamin, ou seja, a transfiguração da política em algo sem conteúdo real, sem essência, associada apenas à aparência muitas vezes forjada pelo poder instituído. Essa participação falseada, que não transforma objetivamente a realidade e tão menos a consciência dos trabalhadores no sentido de sua emancipação, hoje serve de sustentáculo ao que chamamos de democracia moderna (ou representativa), ou seja, à manutenção do status quo, da ordem hegemônica capitalista de exploração e opressão da classe trabalhadora como um todo. Perpetuada pela mídia e pelos meios de comunicação, mais especificamente pelos canais de televisão e jornais tradicionais, a estetização da política nos dias atuais também se desdobra em guerra: uma guerra de narrativas e discursos capaz de impulsionar uma guerra corporal, espacial e urbana.

Entra em cena, portanto, uma guerra de símbolos e narrativas nas quais os elementos "povo", "nação" e "cidadão" prefiguram sem trégua em contraposição às alegorias "vândalos", "anarquistas", "comunistas", "radicais". Ocorre todo um movimento no sentido de desarticular a massa de trabalhadores para que não ocorra o fortalecimento dos grupos de resistência e oposição à ordem estabelecida. Ao se identificar com as primeiras alegorias (povo, cidadão, etc.) a população se coloca do lado oposto de quem se insurge, reafirmando a ideologia dominante enquanto tal. Mas, nem sempre esse projeto político-ideológico se consolida e, nesse momento, as técnicas de reprodução em massa mostram a importância da "reprodução das massas", ou seja, ao ver/sentir-se representado em ações 
insurgentes noticiadas pela mídia, o trabalhador/ estudante pode assumir a resistência e a desobediência civil como sendo o "seu lado" na guerra.

Eis que surge uma possibilidade de romper com o estranhamento coletivo ao qual foi subordinada a classe trabalhadora. Uma faísca de resistência que se incendeia tal como pólvora pelos "fios" urbanos. A ocupação das ruas, do espaço público e da cidade é o resultado direto de uma (re)ação, pois, conforme aponta Harvey (2014),

De fato é nas cidades que as classes abastadas são mais vulneráveis, não necessariamente enquanto pessoas, mas quanto ao valor dos bens que controlam. É por esse motivo que o Estado capitalista se prepara continuamente para lutas urbanas militarizadas como linha de frente da luta de classes nos próximos anos. (HARVEY, 2014, p. 235)

É nesse momento que entram em cena os ataques aos símbolos do capital, ou seja, bancos, concessionárias e revendedoras de veículos, grandes empresas, etc.. Pois, nos recordemos: trata-se não só de uma guerra concreta, que afeta bens materiais, mas também de uma guerra discursiva. E nesse momento é crucial que tratemos dos símbolos, dos significados, que se afetem os signos da dominação e que se fortaleça o polo da resistência.

Em contraponto a ação insurgente tem-se uma reordenação do discurso dos canais de dominação ideológica. Faz-se necessário reduzir a zero a divulgação das insurgências para que outros trabalhadores não se "contaminem". As armas de guerra da ordem hegemônica são, portanto, desproporcionais às da resistência. Seja ela discursiva ou espacial, a guerra traz consigo destruição: alteram-se os signos, as imagens coletivas, as formas organizativas, as consignas, algumas doutrinas, mas permanecem as máximas da ordem vigente ainda que disfarçadas com novas roupagens. Conforme afirma Tarrow (2009) em relação à disputa de significados,

Na luta pelos significados, em que os movimentos estão sempre engajados, é raro não ficarem em desvantagem quando competem com os estados, que não apenas controlam os meios de repressão, mas têm à sua disposição instrumentos importantes para a construção de significados. A luta entre os estados e movimentos ocorre não apenas nas ruas, mas nas disputas pela significação. (TARROW, 2009, p. 41) 
Vejamos agora algumas situações de guerra discursiva e luta urbana que vêm marcando o início do século XXI no mundo e no Brasil, com especial atenção aos movimentos sociais urbanos pós 2013 e às ocupações de estudantes que irromperam nos anos de 2015 e 2016 no Brasil desafiando a crescente estetização da política. Vejamos ainda alguns elementos do que chamamos de "simulacro democrático" enquanto regime político vigente no atual mundo neoliberal.

\section{A reativação da luta urbana e do "direito à cidade"}

Desde a chegada do século XXI, uma mudança no quadro da mobilização popular tem marcado o desenvolvimento da luta de classes mundial. Embora difusas e aparentemente desconectadas, ocorreram diversas mobilizações, em diferentes tempos e espaços, que romperam minimamente com o declínio das lutas sociais vivenciado entre as décadas de 1970 e 1990. No contexto das lutas globais, diante do acirramento da crise do capital no plano internacional (a partir de 2008, principalmente), observou-se ao final de 2010 e início de 2011, o despontar de inúmeras mobilizações que se iniciaram com os movimentos populares antirregime no norte da África (deposição das ditaduras Tunísia, no Egito, na Líbia e no Iêmen) avançando para movimentos de forte oposição aos planos de austeridade dos governos neoliberais na Espanha (M15M, Movimento dos Indignados), Portugal (M12M, Geração à Rasca) e Grécia (Praça Syntagma), alcançou os subúrbios de Londres chegando até mesmo aos Estados Unidos (Occupy Wall Street), América Latina (Chile) e Rússia (HARVEY et al., 2012, p. 7). Esse despontar de mobilizações inundou o cenário do capitalismo globalizado de novas experiências de luta e resistência popular.

No Brasil, os reflexos da crise econômica mundial começam a se tornar visíveis a partir da década de 2010. Enquanto isso, a aplicação do receituário neoliberal diluído em políticas sociais compensatórias ocultou a ampliação da desigualdade social, da concentração de renda, e ampliação do poder de dominação da elite (HARVEY, 2014, p. 47) consolidando o que Felipe Demier (2017) chama de "democracia blindada". A ampliação dos níveis de desigualdade reverberou no aprofundamento da segregação socioespacial e na hegemonia da propriedade privada e dos interesses individuais sobre os interesses coletivos, 
Como em todas as fases anteriores, essa expansão muito recente e radical do processo urbano trouxe consigo incríveis transformações no estilo de vida. A qualidade da vida urbana tornou-se uma mercadoria para os que têm dinheiro, como aconteceu com a própria cidade em um mundo no qual o consumismo, o turismo, as atividades culturais e baseadas no conhecimento, assim como o eterno recurso à economia do espetáculo, tornaram-se aspectos fundamentais da economia política urbana, inclusive na Índia e na China. (HARVEY, 2014, p. 46)

A qualidade de vida urbana e a liberdade de usufruto do espaço foram reduzidas a possibilidade de consumo para aqueles que têm dinheiro, alimentando o individualismo e gerando cidades cada vez mais segregadas, excludentes e propensas ao conflito (HARVEY, 2014, p. 47). A cidade murada e fragmentada traduz o cenário urbano contemporâneo, e como afirma Harvey,

Nessas condições, os ideais de identidade urbana, cidadania e pertença, de uma política urbana coerente, já ameaçados pelo mal-estar da ética neoliberal individualista, tornamse muito mais difíceis de manter. Até mesmo a ideia de que a cidade poderia funcionar como um corpo político coletivo, um lugar no qual e a partir do qual poderiam surgir movimentos sociais progressivos, parece - pelo menos superficialmente - cada vez mais implausível. (HARVEY, 2014, p. 49)

Por meio das Parcerias Público-Privadas, arranjos que promovem uma verdadeira "democracia direta do capital ou da burguesia" para retomar uma expressão utilizada por Vainer (2000), ${ }^{1}$ as reestruturações urbanas absorvem os excedentes da produção ao mesmo tempo que promovem uma "destruição criativa" que atinge diretamente a classe

\footnotetext{
${ }^{1}$ Expressão utilizada pelo autor Carlos Vainer para denominar os processos em que as negociações sobre o planejamento estratégico de determinada cidade/ região são conduzidos "de maneira absolutamente autoritária e fechada à participação de segmentos de escassa relevância estratégica [...]" (VAINER, 2000, p. 90) a exemplo da experiência com o Plano Estratégico do Rio de Janeiro. Ver VAINER, Carlos B. "Os liberais também fazem planejamento urbano? Glosas ao 'Plano Estratégico' da Cidade do Rio de Janeiro".
} 
trabalhadora, que se acomoda nas áreas mais precarizadas ou decadentes dos centros, nas favelas, nas periferias e nas franjas urbanas.

Diante desse contexto de aprofundamento da crise urbana a chegada do novo milênio recolocou na ordem do dia a luta pelo direito à cidade. A ideia do direito à cidade tal como se apresenta no século XXI, conforme aponta Harvey (2014, p.15), distante de uma retomada dos pensamentos de Henri Lefèbvre ${ }^{2}$ e do contexto das lutas da década de 1960, ressurge como uma nova consigna e se consolida em razão do aprofundamento da precariedade de vida nas cidades. $\mathrm{O}$ direito à cidade no mundo contemporâneo é resultado do somatório das diversas pautas específicas que preenchem o espaço da luta urbana: lutas específicas por moradia, por infraestrutura, por mobilidade, transporte público, contra as remoções, contra a segregação dentre outras tantas. Nesse sentido, ocorre uma intercessão entre os diversos movimentos sociais urbanos no sentido de agregar forças e aumentar o poder de barganha frente ao Estado, ao capital imobiliário e ao capital financeiro. Contudo, “[...] o direito à cidade é um significante vazio. Tudo depende de quem lhe vai conferir significado [...] A própria definição de 'direito' é objeto de uma luta, e essa luta deve ser concomitante com a luta por materializá-lo" (HARVEY, 2014, p. 20). Nesse sentido, continua Harvey,

Nossa tarefa política, sugere Lefebvre, consiste em imaginar e reconstituir um tipo totalmente novo de cidade a partir do repulsivo caos de um desenfreado capital globalizante e urbanizador. Contudo, isso não pode ocorrer sem a criação de um vigoroso movimento anticapitalista cujo objetivo central seja a transformação da vida urbana do nosso cotidiano. (HARVEY, 2014, p. 20).

Embora o ressurgimento da expressão "direito à cidade" não tenha se dado pela reativação da obra de Lefèbvre, a retomada dos pressupostos do autor se faz necessária para avançarmos no preenchimento desse

\footnotetext{
${ }^{2}$ Em 1967 o filósofo francês Henri Lefèbvre escreveu o ensaio "Le detroit à la ville" [O direito à cidade] para as comemorações do centenário do volume I d'O Capital de Karl Marx. Às vésperas da insurgência conhecida como maio de 1968, Lefebvre escreveu sobre a necessidade de "criar uma vida urbana alternativa que fosse menos alienada, mais significativa e divertida" e não menos "conflitante e dialética, aberta ao futuro, aos embates (tanto temíveis como prazerosos), e à eterna busca de uma novidade incognoscível” (HARVEY, 2014, p. 11).
} 
significante. É necessário ir além da leitura contemporânea que reivindica o acesso individual e/ou coletivo aos recursos da cidade, à infraestrutura urbana e seus equipamentos. Para Lefèbvre, o direito à cidade inclui o direito a reinventar e recriar a cidade, decidir coletivamente pelos rumos e processos de urbanização. É, sobretudo, "o direito à obra (à atividade participante) e o direito à apropriação (bem distinto do direito à propriedade)" (LEFEBVRE, 2001, p.134). O autor então nos apresenta uma nova abordagem em relação às "necessidades sociais inerentes à sociedade urbana" ao diferenciar a sociedade urbana da atual sociedade de consumo. A partir da sociedade urbana surgiriam novas perspectivas de interação social nas quais as atividades criadoras (de obra) são elementos centrais e se articulam com o jogo, a sexualidade, os atos (expressões) corporais, a arte e o conhecimento como forma de superação da "divisão parcelar dos trabalhos" (LEFEBVRE, 2001, p. 105). Para o autor,

As necessidades sociais têm um fundamento antropológico; opostas e complementares, compreendem a necessidade de segurança e a de abertura, a necessidade de certeza e a necessidade de aventura, a da organização do trabalho e a do jogo, as necessidades de previsibilidade e do imprevisto, de unidade e de diferença, de isolamento e de encontro, de trocas e de investimentos, de independência (e mesmo de solidão) e de comunicação, de imediaticidade e de perspectiva a longo prazo. [...] Trata-se da necessidade de uma atividade criadora, de obra (e não apenas de produtos e de bens materiais consumíveis), necessidades de informação, de simbolismo, de imaginário e de atividades lúdicas. (LEFEBVRE, 2001, p. 105)

Nesse sentido, faz-se necessário construir uma nova práxis e um novo homem, "o homem da sociedade urbana", afastando os obstáculos que limitam essa caminhada como, por exemplo, as ideologias, os mitos e as falsas estratégias. "A vida urbana ainda não começou" (LEFEBVRE, 2001, p. 108) afirma Lefèbvre, e complementa que "apenas grupos, classes ou frações de classes sociais capazes de iniciativas revolucionárias podem se encarregar das [...] soluções para os problemas urbanos; com essas forças sociais e políticas, a cidade renovada se tornará a obra" (LEFEBVRE, 2001, p. 113).

Qual seria, no entanto, a possibilidade real de promoção de uma iniciativa revolucionária de construção da sociedade urbana? Lefebvre 
aponta que em meio à estrutura dominante existem brechas, "abismos". Contudo, "esses vazios não provêm do acaso. São também os lugares do possível, elementos flutuantes ou dispersos, mas não a força capaz de os reunir" (LEFEBVRE, 2001, p. 115). Nesse sentido seria necessária a realização de uma metamorfose radical.

Conforme aponta Harvey (2014),

A totalidade do sistema capitalista de acumulação infinita, assim como suas estruturas relacionadas de poder de exploração de classe e do Estado, deve ser derrubada e substituída. Reivindicar o direito à cidade é uma estação intermediária na estrada que conduz a esse objetivo. Isso nunca poderá ser um objetivo em si mesmo, ainda que cada vez mais pareça ser um dos caminhos mais propícios a se seguir (HARVEY, 2014, p. 24).

É dentro dessa perspectiva, portanto, que devemos retomar o sentido lefebvriano, que pressupõe tomar a luta pelo direito à cidade no seu aspecto mais revolucionário, para além das conquistas imediatas (ainda que essas estejam contidas), como parte de uma luta anticapitalista.

\section{Os limites da mediação na democracia brasileira e outros elementos}

Diante das transformações econômicas, políticas e sociais ocorridas nas décadas de 1980 e 1990, com destaque para a expansão do neoliberalismo e suas contrarreformas frente a crise do capital, as democracias liberais passaram a apresentar uma nova forma a qual Felipe Demier (2017) chama de "democracia liberal de novo tipo" ou "democracia blindada". O autor aponta que, diferentemente do modelo democrático do pós- segunda guerra (welfare state ou bemestar social) marcado pela forte organização popular que galgou um pacto de concessões materiais à classe trabalhadora, esse novo formato vigente, a democracia blindada, "têm seus núcleos políticos decisórios (ministérios, secretarias, parlamentos, etc.) praticamente impermeáveis às demandas populares" (DEMIER, 2017, p. 38). Na democracia blindada, argumenta Demier (2017, p. 41), parte dos organismos do Estado e do poder Judiciário são comandados pelos representantes políticos (alheios à classe trabalhadora e seus interesses) e "prepostos comerciais da classe dominante", que seguem implementando (de forma mais ou menos 
explícita) a plataforma neoliberal. O autor aponta que diante desse quadro a disputa política acaba reduzida a um único projeto, tendo em vista que os partidos da esquerda (socialdemocratas e/ou eurocomunistas) passaram a aplicar um "programa essencialmente contrarreformista (mesclado a políticas públicas focalizadas, os chamados programas sociais compensatórios)" (DEMIER, 2017, p. 44). Ainda em relação aos partidos de "esquerda" o autor salienta que, chegando ao poder, esses partidos exercem um importante papel de direção, amparados pelo seu passado vinculado aos trabalhadores e suas organizações, contribuindo para o "apassivamento dos setores subalternos da sociedade" e restringindo "as liberdades de manifestação popular” (DEMIER, 2017, p. 45). Acrescentase aqui a mídia que cumpre o papel de validar os discursos hegemônicos construindo consensos, e que Felipe Demier apresenta como sendo um alicerce central da "democracia blindada":

Por meio de seu discurso ideológico, que se pronuncia normativamente sobre vários âmbitos da vida social, as corporações midiáticas ajudam a executar cotidianamente a blindagem das atuais democracias. Em um contexto de contrarreformas e ataques aos direitos em geral, a grande imprensa torna-se responsável pelo fornecimento de uma parte cada vez maior dos ingredientes consensuais do regime democrático contemporâneo. Diferentemente de formatações anteriores da democracia liberal, a grande imprensa parece, nas democracias blindadas, executar uma função interna, basilar ao regime, e não mais apenas uma função complementar, "externa", limitada a apoiar/ referendar os mecanismos de dominação vigentes. Agora, ela é um dos sujeitos que engendra estes próprios mecanismos. (DEMIER, 2017, p. 46)

Esse formato de democracia restrita que surge e se fortalece nos países do norte também foi utilizado no receituário das transições democráticas na América Latina. No Brasil a ativação da "blindagem" dessa democracia ocorre na passagem do século XX para o século XXI, uma vez que no momento da transição democrática ocorria um processo de reativação da sociedade civil, com forte organização da classe trabalhadora ("novo sindicalismo", movimentos sociais) o que levou à consolidação de uma democracia liberal, sustentada por uma Constituição híbrida de valores progressistas e conservadores. Assim, Demier (2017, 
p. 62) aponta que o momento principal da efetivação da "democracia restrita" no Brasil ocorre com a chegada do Partido dos Trabalhadores ao governo federal, que mantém a aplicação de contrarreformas contrabalanceando os impactos sobre a classe trabalhadora com "políticas sociais focalizadas":

Os quatro mandatos petistas no governo federal (ou melhor, três mandatos e meio) combinaram a manutenção dos eixos centrais da política econômica levada a cabo por F. H. Cardoso (superávit primário, pagamento das dívidas interna e externa, juros altos, apoio ao agronegócio, etc.) com uma significativa redução do desemprego, um sensível aumento do salário mínimo, a ampliação do mercado consumidor e uma expressiva expansão das [políticas] sociais compensatórias. Substituindo um projeto de pacto social por um de concertação social, o PT, no poder, contribuiu, portanto, para a blindagem do regime democrático-liberal brasileiro, cada vez mais imunizado contra as pressões populares. (DEMIER, 2017, p. 62, 63)

É no âmbito desta "democracia restrita" que entram em cena novamente os movimentos e as manifestações populares de grandes proporções, que em junho de 2013 irromperam no cenário brasileiro até então marcado por uma passividade e paralisia social. Ao longo dos anos de 2000 a 2013 os movimentos sociais urbanos e as vanguardas político-sindicais da classe trabalhadora realizaram suas lutas e disputas por políticas públicas, infraestrutura, equipamentos urbanos, moradia, educação, dentre outras pautas de igual relevância, mas se esbarraram na indiferença do conjunto da população para com as lutas sociais e esbarraram-se, principalmente, na adaptação institucional de uma parcela significativa das organizações da classe trabalhadora e movimentos sociais. Foi nesse contexto que surgiram as mobilizações de junho de 2013 no Brasil. Começaram como mobilizações de vanguarda contra o aumento da passagem, "se tornaram multitudinárias e, depois de décadas de contrarreformas, exigiam dentre outras demandas, Saúde, Educação e Transporte públicos baratos e de qualidade" (DEMIER, 2017, p. 69). O movimento se espalhou de ampliou das capitais do Brasil para as cidades grandes e médias chegando até mesmo nas microlocalidades. A ação direta via ocupação do espaço público teria ocorrido em virtude do esgotamento dos canais de mediação política no interior do regime. 


\section{Ação coletiva e desobediência civil: o protagonismo da juventude secundarista}

A proposta de reorganização escolar do governador de São Paulo Geraldo Alckmin (PSDB), anunciada ao final do ano de 2015, não poderia ter recebido uma resposta tão 'a altura' quanto de fato ocorreu com as 213 unidades escolares ocupadas pelos estudantes do ensino fundamental e médio, em 2 de dezembro de 2015, momento auge das ocupações. A reorganização escolar, que contava com o fechamento de 94 escolas e com a transferência de mais de 300 mil estudantes não foi debatida com a comunidade escolar e demonstrou ser um claro projeto de corte de gastos, com possíveis demissões de terceirizados, sucateamento da educação pública e com a geração de salas ainda mais cheias tendo em vista as atuais condições da educação pública no país.

Após repressões violentas aos estudantes, característica dos governos conservadores dentre os quais se destaca o governo de Geraldo Alckmin, os estudantes conquistaram uma vitória sem precedentes e conseguiram suspender o projeto de reorganização escolar, conforme segunda decisão do Tribunal de Justiça de São Paulo, expedida em 14 de janeiro de 2016.

As ocupações escolares, mais do que simples impedimento à implementação do projeto de reorganização escolar orquestrado sem debates e sem a participação do conjunto da sociedade, demonstraram como o desgaste com as péssimas condições de vida nas cidades, dentre as quais se destacam a moradia, o transporte, a educação e o lazer podem levar à efervescência da luta por direitos. As lutas da juventude secundaristas mostraram que as manifestações de junho de 2013, escancaradas de forma abrupta e intensa, não se perderam na polarização política que acompanhou as eleições de 2014.

A garra da nova geração na luta por participação e reconhecimento de direitos não está descolada da formação de uma consciência crítica, capaz de engendrar não só grandes lutas pela mudança da estrutura educacional sucateada, mas também engendrar as lutas pelo direito à cidade, "Essa política de construir mais cadeias e fechar escola prejudica principalmente os mais pobres, não querem que tenhamos estudo", frase de uma estudante da escola estadual Fernão Dias, apresentada na matéria do El país no dia 12 de novembro de 2015, intitulada "O dia em que cem policiais sitiaram uma escola ocupada em São Paulo". ${ }^{3}$

${ }^{3}$ Disponível em: <http://brasil.elpais.com/brasil/2015/11/11/politica/1447273812_ 584840.html>. Acesso em: 27 maio 2016. 
As insurgências contra a reorganização escolar em São Paulo, ao contrário do que deseja o poder dominante, não foram abafadas pela violência da Polícia (entendida aqui como violência do Estado) nem pela grande mídia, que noticiou apenas o inevitável. Ocorreu que a repressão violenta como tentativa radical de manutenção do controle e da ordem despertou na consciência das novas gerações a inspiração e os motes de uma nova insurgência. Em determinados momentos, a repercussão da violência da polícia contra manifestantes de diferentes categorias - sejam estudantes, professores ou movimentos sociais - geraram manifestações ainda maiores do que as iniciais envolvendo diversos setores da sociedade.

Elemento novo nesse contexto, com grande destaque e com enorme papel insurgente, a internet e a circulação de informações por meios alternativos à grande mídia, aprofundou as discussões sobre a dominação do Estado e sobre a necessária participação, luta por direitos, legitimidade e democracia direta.

Após o levante da juventude em São Paulo ocupações de escolas ocorreram em vários estados do país. Em Goiás, sob a gestão de Marconi Perillo (PSDB), o plano para a educação foi mais agressivo e incluiu nas metas do plano piloto para a educação o fechamento das escolas de período integral, o repasse de algumas escolas para a administração das Organizações Sociais (OSs) e de outras para a Secretaria de Segurança Pública promovendo a chamada militarização escolar.

As ocupações em Goiás e a luta dos estudantes contra o projeto do governo enfrentaram inúmeros obstáculos. As manifestações foram violentamente reprimidas havendo, inclusive, alunos detidos e presos. $\mathrm{Na}$ rede social do movimento, os estudantes questionaram a truculência da polícia e a repressão nos atos contra o governo enquanto os atos apoiados pelas escolas militares contra o aborto, por exemplo, foram totalmente e 'democraticamente' aceitos pelas forças militares, demonstrando o claro corte ideológico da repressão policial:

\section{Lutar não é crime}

Hoje, em um ato pacífico, contra a OS's fomos reprimidos pela PM (aquela que tem o papel de cuidar da sua segurança, não é mesmo?). Pedimos para o Secretário de Ciências e Desenvolvimento descer e receber nosso documento, com todas a nossas pautas. Ele não desceu, mas mandou a mão do estado pra cima de estudantes que 
lutam por uma educação melhor. Prenderam, jogaram bombas de efeito moral, atiraram e bateram em estudantes. Enquanto isso, acontecia um ato contra a legalização do aborto organizado pela SEDUCE, que levou ônibus com estudantes de colégios militares para essa "passeata", mas a polícia não reprimiu esses estudantes, será por quê? Essa, é a "democracia" em que vivemos! (postagem na rede social "Secundaristas em Luta - GO”, 20/05/16)

A luta de São Paulo e Goiás inspirou os alunos do Rio de Janeiro que emplacaram, em 02 de maio, 65 colégios ocupados. A ocupação seguiu cobrando direitos, lutando por uma educação pública de qualidade e apoiando a greve de aproximadamente $80 \%$ dos professores da rede estadual. O governador do Rio de Janeiro, Luiz Fernando Pezão (PMDB), e a Secretaria Estadual de Educação adotaram um sistema de bonificação às escolas e aos professores que obtivessem melhor desempenho, a partir de um sistema de avaliações sequenciais (SAERJ - Sistema de Avaliação da educação do RJ), uma política de produtividade e direcionamento de recursos que prejudica o desenvolvimento da educação pública como um todo e que, portanto, é uma pauta importante na luta dos estudantes,

“É um sistema meritocrático. Queremos que o dinheiro seja distribuído de maneira igual, democraticamente, entre todas as escolas. Todas têm carências." afirma o ex-aluno Gabriel Richard, de 18 anos, um dos articuladores da ocupação. (El país, 2 maio 2016)

Diferentemente das outras regiões, enquanto o movimento das ocupações no Rio de Janeiro crescia e pressionava o Governo, surgiu um movimento paralelo, também de estudantes que considerava ilegítimo ocupar as escolas. O crescimento desse movimento colocou em voga as contradições de uma sociedade complexa, de relações conflituosas e opiniões divergentes. Neste caso, o conflito, que deveria servir para alimentar o debate e construir uma dinâmica de participação e crescimento dos estudantes e sua luta, como é de praxe na sociedade contemporânea, apenas fortaleceu um dos lados do cabo de guerra, representado pela ordem vigente, na busca pelas reintegrações de posse das escolas. Mas as ocupações mantiveram sua força e o governo decretou o recesso escolar.

\footnotetext{
${ }^{4}$ Disponível em: <http://brasil.elpais.com/brasil/2016/04/29/politica/1461955632_
} 442061.html>. Acesso em: 27 maio 2016. 
Num país em que a escola pública foi sucateada ao extremo e que a qualidade do ensino, da infraestrutura das escolas e dos modelos de participação e cidadania são perversos, os governos intentam ao máximo deixar os serviços públicos de tão baixa qualidade a ponto de justificarem a privatização. A culpabilização dos estudantes que ocupam as escolas pelo tempo perdido, sem aulas, ou dos professores em greve, vai ser sempre maior do que qualquer conquista, pois o sistema assim se utiliza das ideologias disseminando falsas verdades. Mas os estudantes estão atentos e cada vez mais conscientes do poder que têm,

Enquanto o impasse permanece, as salas de aula continuam vazias e transformadas em dormitórios e locais de assembleia e debate. O prejuízo para os alunos é grave, segundo o chefe de gabinete da Secretaria de Educação. "Após a greve, os professores voltarão ao seus empregos com seus salários, mesmo sendo baixos, o secretário pode ser outro, mas o aluno que perde esse ano letivo em ano de Olimpíada [com férias adaptadas ao evento] e de eleições municipais [que vai alterar a rotina da cidade], esse aluno já não recupera. Há 1.200 alunos ocupando e 49.000 perdendo aula." Cruz concorda nos prejuízos e na dificuldade para recuperar as aulas perdidas: "Ninguém está ganhando, mas está se reafirmando um protagonismo juvenil forte e importante". (El país, 2 maio 2016)

$\mathrm{Na}$ rede social das ocupações do Rio de janeiro os alunos apresentaram testemunhos, imagens e vídeos da violência policial que ocorria no dia-a-dia das ocupações e reafirmaram a força do movimento secundarista,

A ocupação de ontem da SEEDUC foi marcada por violência, truculência e abuso por parte do Estado e da polícia. Mantendo os alunos por horas em cárcere privado após a tomada do prédio, os "oficiais da lei" só conseguiram "se superar" quando, por meio da tropa de CHOQUE, espancaram alunos no local - houveram feridos e desmaiados. Esse é um exemplo do porquê essa luta é de todos nós e só tem que se fortalecer. Cada vez mais o

\footnotetext{
${ }^{5}$ Disponível em: <http://brasil.elpais.com/brasil/2016/04/29/politica/1461955632_ 442061.html>. Acesso em: 27 maio 2016.
} 
secretário de educação, o governador e a polícia mostram sua verdadeira cara, por temer o que pode significar para eles a força do movimento secundarista. NÃO PASSARÃO! A LUTA CONTINUA! (postagem na rede social "Escolas do RJ em luta", 21/05/16)

Em 2016 o movimento secundarista em São Paulo retornou às ruas contra os desvios de verba na compra da merenda da rede estadual reivindicando dos deputados que aprovassem a abertura da CPI (Comissão Parlamentar de Inquérito) da Merenda. Em maio os estudantes ocuparam a Assembleia Legislativa do Estado de São Paulo (ALESP) cujo presidente, deputado Fernando Capez (PSDB), havia sido citado nos esquemas de corrupção da merenda. Em 17 de maio de 2016, os estudantes comemoraram a abertura da CPI em caráter de urgência.

As ocupações das escolas de ensino fundamental, médio e técnico se estenderam por vários estados do Brasil de norte a sul. No Rio grande do Sul o número de escolas ocupadas ultrapassou o número de 150 unidades em maio de 2016, segundo reportagem do G1 . ${ }^{6}$ No Ceará, em reportagem do dia 25 de maio, foram apontadas $52^{7}$ escolas ocupadas.

\section{Considerações Finais}

As ocupações escolares tratadas anteriormente, tanto das escolas estaduais e técnicas quanto da ALESP, além de tantas outras não mencionadas nesse artigo e que possuem igual relevância no contexto da luta por direitos, demonstram claramente que há um esvaziamento do espaço institucional da participação, da legitimidade do voto e da democracia representativa. Portanto é preciso reinventar a participação, e recriar esferas de pressão, como aponta Boaventura de Souza Santos,

As diferentes formas de participação podem, assim, aparecer em versões que tendem a reforçar os modos hegemônicos de conhecimento e de exercício do poder político - organizadas "de cima para baixo" (...). Mas elas podem surgir também sob formas contra-hegemônicas,

\footnotetext{
${ }^{6}$ Disponível em: <http://g1.globo.com/rs/rio-grande-do-sul/noticia/2016/05/passa-de100-o-numero-de-escolas-ocupadas-no-rs-diz-sindicato.html>. Acesso em: 28 maio 2016. ${ }^{7}$ Disponível em: <http://g1.globo.com/ceara/noticia/2016/05/greve-dos-professoresdo-ce-chega-um-mes-com-52-escolas-ocupadas.html>. Acesso em: 28 maio 2016.
} 
organizadas "de baixo para cima", com critérios mais amplos de inclusão, admissão de uma diversidade de modos de expressão, de conhecimentos e de competências, de experiências, afirmação do caráter agonístico dos exercícios de participação, inclusão de temas considerados irrelevantes ou "fora de limites" pelos atores hegemônicos, pressão sob a decisão, articulação com outras formas de mobilização e de ação coletiva. (SANTOS, 2005, p. 70)

A ocupação física dos espaços institucionais, espaços em que as atividades (escolar, política, social) se realizam, cumprem um importante papel de impedir que a opinião da população seja ignorada e que o Estado aprove os seus projetos à revelia do debate e da aceitação pública. Elas reinventam o espaço participativo onde todos têm vez e voz.

A democracia representativa no Brasil passa por um momento crítico dado o alcance e a visibilidade da corrupção dos representantes eleitos que associada à carestia de vida e retirada de direitos gera uma situação de insurgência setorial, que tende a se generalizar com o agravamento e acirramento das tensões sociais.

A ocupação dos espaços institucionais demonstra que a falta de diálogo entre a população e seus representantes chegou a níveis não mais tolerados requerendo medidas de desobediência civil e insurgência as quais não temem a força do Estado repressor.

No entanto, mais do que insurgentes, as ocupações são espaços diferenciais em que a experimentação de um novo modo de articulação, representação, legitimidade e cultura são engendradas podendo vir a impulsionar rupturas com a forma obsoleta de vida nas cidades contemporâneas abrindo espaço para a formação de novos sujeitos. Conforme afirma Evelina Dagnino (1994), "na organização desses movimentos sociais, a luta por direitos - tanto o direito a igualdade como o direito às diferenças - constituiu a base fundamental para a emergência de uma nova noção de cidadania.” Ou, ainda:

(...) Incorporando características da sociedade contemporânea, como o papel das subjetividades, a emergência de sujeitos sociais de novo tipo e de direitos de novo tipo, a ampliação do espaço da política, essa é uma estratégia que reconhece e enfatiza o caráter intrínseco e constitutivo da transformação cultural para a construção democrática. (DAGNINO, 1994) 
Assim, As ocupações secundaristas, caso apresentado nesse artigo, ao contrário do que propagandeou a grande mídia, não são depredadora, mas são elas próprias a proteção do patrimônio público que o Estado insiste em sucatear.

Nas ocupações ocorreram eventos e aulas públicas com o apoio dos professores, cine-debates, oficinas de leitura e arte, assembleias, rodas de conversa e shows culturais. As tarefas eram desenvolvidas por comissões que se organizavam segundo as temáticas "estrutura", "alimentação", "segurança", "comunicação", etc. Mas o que mais se destacou foi a ampliação da discussão política, que torna possível uma mudança nos paradigmas do saber hegemônico: "estamos organizando debates para discutir as coisas, os problemas das sociedades, vão ter temas que estão enraizados em nossa sociedade como o assassinato de jovens pobres nas favelas, a questão da mulher e outras temas atuais". ${ }^{8}$

A experiência cultural, política, coletiva e organizativa das ocupações são marcadas por inúmeras contradições, como não poderia deixar de acontecer num modelo de sociedade dominado por relações de exploração, ideologias de opressão e reafirmação de saberes hegemônicos e dominantes. Mas as ocupações conseguiram trabalhar com os conflitos na sustentação de um objetivo coletivo e maior. Demonstraram ser experiências empíricas de espaços de autonomia que seguem mostrando seu potencial de transformação.

\section{Referências}

BENJAMIN, Walter. A obra de arte da era de sua reprodutibilidade técnica. In: GRÜNEWALD, José Lino. A ideia do cinema. Rio de Janeiro: Civilização Brasileira, 1969.

DAGNINO, E. Os movimentos sociais e a emergência de uma nova noção de cidadania. In: . (Org.). Os anos 90: política e sociedade no Brasil. São Paulo: Brasiliense, 1994. p.103-115.

\footnotetext{
${ }^{8}$ Trecho da entrevista do midiacoletiva.org com um representante da Ocupação do Colégio Estadual Visconde de Cairú, zona sul do Rio de Janeiro. Disponível em: $<\mathrm{http}$ ://midiacoletiva.org/o-impressionante-cotidiano-de-uma-escola-ocupada-no-riode-janeiro-2/>. Acesso em: 28 maio 2016.
} 
DEMIER, Felipe. Depois do golpe: a dialética da democracia blindada no Brasil. 1. ed. Rio de Janeiro: Mauad X, 2017.

HARVEY, David et al. Ocuppy. Tradução de João Alexandre Peschansky et al. São Paulo: Boitempo: Carta Maior, 2012.

HARVEY, David. Cidades rebeldes: do direito à cidade à revolução urbana. Tradução de Jeferson Camargo. São Paulo: Martins Fontes, 2014.

LEFEBVRE, Henri. O direito à cidade. Tradução de Rubens Eduardo Frias. 5. ed. São Paulo: Centauro, 2001.

SANTOS, B. S.; MENESES, M. P.; NUNES, J. A. Para ampliar o cânone da ciência: a diversidade epistemológica do mundo. In: SANTOS, Boaventura de Souza (Org.). Semear outras soluções: os caminhos da biodiversidade e dos conhecimentos rivais. Rio de Janeiro: Civilizacão Brasileira, 2005.

TARROW, Sidney. O poder em movimento: movimentos sociais e confronto político. Tradução de Ana Maria Sallum. Petrópolis, RJ: Vozes, 2009.

\section{Internet}

$<$ http://midiacoletiva.org/o-impressionante-cotidiano-de-uma-escolaocupada-no-rio-de-janeiro-2/.> Acesso em: 28 maio 2016.

$<$ http://brasil.elpais.com/brasil/2015/11/11/politica/1447273812 584840.html >. Acesso em: 27 maio 2016.

$<$ http://brasil.elpais.com/brasil/2015/12/18/politica/1450457576_ 034545.html>. Acesso em: 27 maio 2016.

$<$ http://brasil.elpais.com/brasil/2016/04/29/politica/1461955632_ 442061.html >. Acesso em: 27 maio 2016.

$<$ http://g1.globo.com/rs/rio-grande-do-sul/noticia/2016/05/passa-de100-o-numero-de-escolas-ocupadas-no-rs-diz-sindicato.html $>$. Acesso em: 28 maio 2016.

Rede social “Ocupação ALESP”, 17/05/16.

Rede social "Secundaristas em Luta - GO", 20/05/16.

Rede social "Escolas do RJ em luta”, 21/05/16. 